The Japan Society of Human Genetics Award Lecture

\title{
CYTOGENETIC ASPECTS OF CANCER-PREDISPOSING GENES
}

\author{
Masao S. SASAKI \\ Department of Mutagenesis, Radiation Biology Center, Kyoto University, \\ Yoshida-konoecho, Sakyo-ku, Kyoto 606, Japan
}

\begin{abstract}
Summary Some human monogenic syndromes are characterized by a high cancer propensity, and provide a pathway to the understanding of genetic origin of human cancers. In this review, cytogenetic insights into the Fanconi's anemia (FA) and retinoblastoma (RB) genes have been presented as the model for recessively and dominantly transmitted cancerprodisposing genes, respectively. Some recessively transmitted genes are unequivocally associated with abnormalities in DNA metabolisms and homozygosity increases the genome instability, and some dominantly inherited genes are categorized into loss-of-function mutation of tumor suppressing genes. While the identified syndromes themselves are uncommon and constitute a minor fraction in population, the heterozygote expression of recessive genes is our major concern of genetic predisposition to cancer, and mutation of tumor suppressing genes, identified as somatic mutation, plays a crucial role in the development of a variety of common cancers. Moreover, their possible non-Mendelian inheritance of mutational susceptibility leads us to an even more rewarding area of cancer genetics.
\end{abstract}

\section{Introduction}

Since cancers are generally recognized as the results of somatic heritable changes in certain genes, it is likely that the genetic factors play an important role in their development. The strong evidence for the genetically determined susceptibility to cancer in man stems from the existence of some cancer-predisposing genetic diseases. The insight into the nature, origin and function of such mutant genes has been my major concern in the study of causation of cancer and cancer genetics in man, and constitutes the aim of this lecture.

Presented at the 33rd Annual Meeting of the Japan Society of Human Genetics, September 8-10, 1988, Sapporo.

佐及木正夫 : 遗伝性発癌素因の細胞遗伝学的研究（学会賞受賞講演） 
My carrier was molded by several prominent teachers, beginning with Professor Sajiro Makino who inspired me to dedicate to learning chromosome science when I was a postgraduate student in Hokkaido University from 1959 to 1964 and studied chromosomes of human cancers in his laboratory (Makino et al., 1964): Professor Amos Norman, who stimulated my interest in chromosome mutagenesis when I was a research fellow at University of California. This approach was applied to cytogenetic studies on cancer-predisposing diseases when I joined Professor Akira Tonomura at Tokyo Medical and Dental University, where the study on chromosomal radiosensitivity of Down's syndrome was my first link between chromosome mutation and genetic predisposition to cancer (Sasaki and Tonomura, 1969). I am also grateful to numerous colleagues with whom I have worked out the past 24 years. In particular, I am indebted to Professor Hiraku Takebe, Kyoto University, who stimulated my work on cancer-predisposing diseases and offered a very productive collaboration and warm friendship for many years.

Apart from syndromes with constitutional genomic imballance such as Down's syndrome, the inherited cancer-predisposing diseases are divided into recessive and dominant diseases, or alternatively preneoplastic state in which mutant gene is not itself neoplastic but increases probability that cancer will develop, and hereditary neoplasm in which cancer is the sole manifestation of the mutant gene. In this review I cannot be comprehensive, but address the possible nature of cancer predisposing genes and their relevance to the development of cancer basing on our cytogenetic studies on Fanconi's anemia and retinoblastoma as examples of these two forms of genetic conditions.

\section{Fanconi anemia gene possibly related with the DNA repair pathways}

In 1968, Cleaver found that the patients with autosomal recessive disease, xeroderma pigmentosum (XP), were defective in the repair of DNA damage induced by ultraviolet light irradiation. Since XP had been known to develop cancers in the sun-exposed area, this discovery had a great impact on the study of mutation and cancer in man since it provided the strong evidence for the essential unity of DNA repair system in a wide range of organisms from bacteria to humans, and for the mutational origin of human cancer. This prompted us to search for the biochemical defects associated with the mutant genes which were responsible for other hereditary diseases of high cancer propensity.

Fanconi's anemia (FA) is also a rare genetic disease transmitted as an autosomal recessive trait. The FA homozygotes are identified by a combination of growth retardation, pigmentation anomaly of the skin and diverse congenital anomalies associated with a progressive insufficiency of the bone marrow leading to pancytopenia. The disease is also characterized by the increased frequency of spontaneous chromosome breakage as categorized into the chromosome breakage syndrome (German, 1969). The disease often leads to the development of leukemia and other cancers provided that the patients do not die before from other sequelae of their disease (German, 1983). 
The rationale of my approach was that the basic unit of interphase chromosome is a single DNA duplex (Sasaki and Norman, 1966), and any interruption in the continuity of chromosome may be directly or indirectly related with the basic DNA metabolism. In relation to the basic defect in FA, of considerable interest was a mutagen specificity to chromosome breakage. A high sensitivity of FA to chromosome breakage, first noted by Schuler et al. (1969) in cultured lymphocytes treated with tetramethanesulfonyl-d-mannit, was later found to be specific to the agents that can introduce interstrand crosslinks into DNA (Sasaki and Tonomura, 1973).

Table 1 shows the mutagen specificity of chromosome breakage in the FA and other relevant chromosome breakage syndromes including XP. Since the XP cells are deficient in the repair of UV-, 4NQO- and DCMC-induced DNA damage as revealed by reduced amount of unscheduled DNA synthesis (Sasaki et al., 1977), chromosomal sensitivity of XP cells is consistent with the idea that the DNA damage which are remained unrepaired will link to chromosome structural aberrations when they are carried over to DNA replication (Evans and Scott, 1969; Sasaki, 1973). By analogy of XP, hypersensitivity of FA cells specifically to MMC strongly indicated that the FA cells might have impaired capacity to cope with MMC-induced damage. This has been confirmed by the experiment to see the change in the chromosome aberration frequency against cell cycle position at the time of mutagen treatment (Sasaki, 1975). As is the case for 4NQO and monofunctional DCMC treatment to the XP cells, bifunctional MMC was equally effective whether the FA cells are treated away from or close in time to the beginning of DNA replication while monofunctional DCMC is dramatically inefficient when treated remote from the $S$ phase like normal cells treated with bifunctional MMC. We interpreted that the removal of MMC-induced preaberration lesions was time-limiting process and the FA cells might be defective in this process. The relevant preaberration lesions may be DNA interstrand crosslinks since the FA cells are hypersensitive specifically to bifunctional or polyfunctional agents such as MMC, busulfan (tetramethyl bis-methanesulfonate), psoralen plus light reaction, nitrogen mustard, diepoxybutane, cis-diammine dichloroplatinum II ( $c i s-\mathrm{Pt}(\mathrm{II})$ ), acetaldehyde, TEPA. Strong evidence for the interstrand crosslinks came from the findings that the FA cells were sensitive to bifunctional MMC while not to its monofunctional derivative (Sasaki and Tonomura, 1973), sensitive to busulfan but not to monofunctional ethylmethanesulfonate (Sasaki,

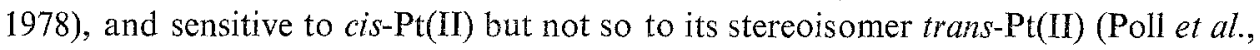
1985).

All the cytogenetic evidence was pointing to the possibility that the FA was defective in the repair of DNA interstrand crosslinks. The defective repair of MMCinduced interstrand crosslinks, first suggested at molecular level (Fujiwara et al., 1977), seems to reside in the initial unhooking process of crosslink repair (Gruenert and Cleaver, 1985; Papadopoulo et al., 1987), but other studies failed to confirm these observations. However, recently, the retention of the interstrand crosslinks in the FA cells was unequivocally demonstrated by the use of ribosomal DNA as a probe (Matsumoto, personal communication). Other aspects of DNA repair in FA, 
M.S. SASAKI

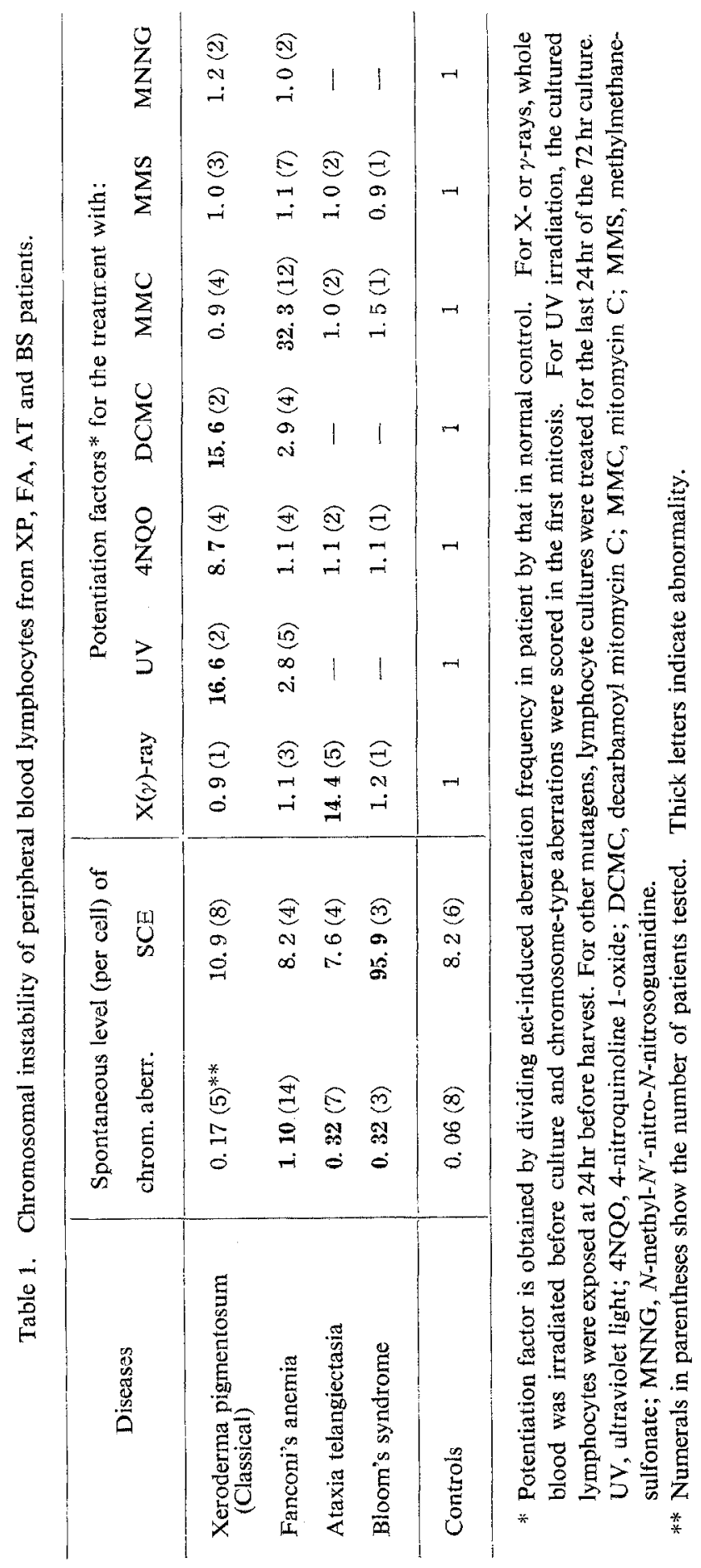

Jpn. J. Human Genet. 
such as abnormalities in exonuclease, ligase activity, NAD level and topoisomerase I, have resulted in controversial findings.

Then, the question may arise as to the origin of increased level of spontaneous chromosome breakage in FA patients. Are there any DNA crosslinking insults in our environment? In this connection, it should be noted that the FA cells are also hypersensitive to oxygen (Joenje et al., 1981). It is thus likely that the FA is defective in the repair of oxidative damage or damage induced by peroxiradicals. Malondialdehyde is one of the most important products of lipid peroxidation and shows strong lethal and mutagenic effects in $E$. coli possibly by forming interstrand crosslinks in DNA (Yonei and Furui, 1981). Acetaldehyde is also widespread and regulariy occurring chemical stuff which forms DNA crosslinks, and the FA cells have been demonstrated to be sensitive to chromosome breakage by acetaldehyde even at doses which are ineffective to the normal cells (Obe et al., 1979).

\section{Nosology of FA and allele frequency}

Although FA is characterized by a combination of a variety of dysmorphisms, no one feature is pathognomonic of this syndrome and the absence of such dysmorphism is not sufficient to rule out the diagnosis. Table 2 summarizes some clinical and chromosomal data of 37 patients which have been suspected to have FA due to the presence of progressive hypoplastic pancytopenia associated with growth retardation and/or other dysmorphisms and referred to us for cytogenetic examinations. Chromosomal data clearly divide these patients into two groups; group A, here I call definitive case, which shows high frequency of spontaneous chromosome breakage and high sensitivity to $\mathrm{MMC}$, and group B which shows normal level of spontaneous chromosome breakage and normal level of MMC potentiation. The spectrum of associated anomalies is also different between two groups. Patients in group B lack most of the symptoms which can be often found in group A such as typical skin pigmentation, thumb anomalies, hypogonadism in males, but are characterized by high frequency of mental retardation which is not common in group A. It is thus highly likely that these two groups have different genetic background. The group B may not be the FA of the Estren-Dameshek type since the patients chategorized into this subgroup have been demonstrated to show an elevated level of spontaneous chromosome breakage as classical FA (Dallapiccola et al., 1980).

Among 26 definitive cases (group A), 9 (34.6\%) had parental consanguinity; either the first or second cousin marriage. Among 45 Japanese patients reported in the literatures but not included in this study, 17 patients $(37.8 \%)$ are offsprings of consanguineous marriage. All together, 26 out of 71 patients $(36.6 \%)$ are born to consanguineous marriage. Taking $1.37 \%$ for the current frequency of cousin marriage in the general population in Japan (Imaizumi et al., 1975), $\mathrm{q}=1.54 \times 10^{-3}$ can be obtained for the gene frequency by the Dahlberg formula. This provides an estimated birth incidence of FA homozygotes of about 1 in $4.2 \times 10^{5}$. If FA allele follows the Hardy-Weinberg law, the frequency of expected heterozygotes is about 1 in 330. This incidence is close to the estimate of Swift (1971), who estimated 
Table 2. Some clinical findings in comparison with the chromosomal instability in lymphocytes of patients suspected to have FA.

\begin{tabular}{|c|c|c|c|c|c|c|c|c|c|c|c|c|c|c|}
\hline Patients & 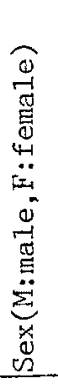 & $\begin{array}{l}\widehat{0} \\
\vdots \\
0 \\
0 \\
0 \\
0 \\
0 \\
0 \\
0 \\
\end{array}$ & 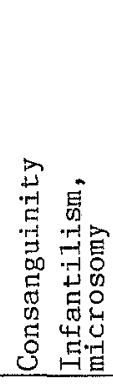 & 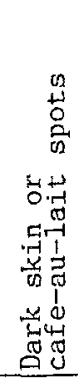 & 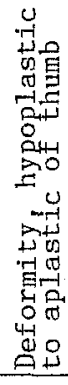 & 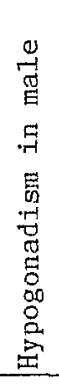 & 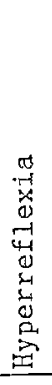 & 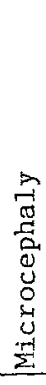 & 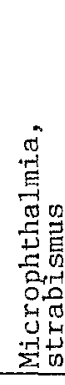 & 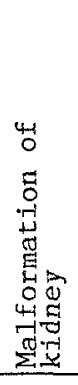 & 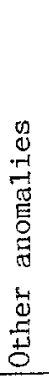 & 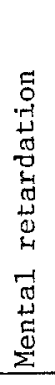 & 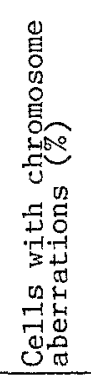 & 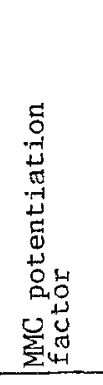 \\
\hline [A] FA1 & M & 6 & + & + & + & + & + & - & - & - & - & - & 60.5 & $-\infty$ \\
\hline FA2 & $\mathrm{F}$ & 6 & - & + & - & & & - & - & - & - & - & 67.5 & - \\
\hline FA5 & F & 6 & - & + & + & & + & - & - & + & + & - & 76.5 & 41.8 \\
\hline FA6 & F & 3 & + & + & + & & - & - & - & & - & - & 91.0 & 112.9 \\
\hline FA7 & M & 4 & + & + & + & + & & - & - & - & + & - & 54.0 & 27.2 \\
\hline FA9 & M & 7 & + & + & + & + & + & - & - & - & - & - & 87.0 & 67.1 \\
\hline FA10 & F & 8 & - & - & - & & - & - & - & - & - & + & 13.0 & 3.9 \\
\hline FA12 & M & 3 & + & + & + & + & + & + & + & - & + & - & 57.0 & 33.2 \\
\hline FA13 & F & 3 & + & + & - & & & - & - & - & - & - & 39.5 & 27.0 \\
\hline FA14 & M & 8 & - & + & - & + & - & - & - & - & - & - & 50.0 & 18.6 \\
\hline FAl7 & M & 11 & - & + & - & + & - & - & - & - & - & - & 39.0 & 9.0 \\
\hline FA18 & M & 7 & - & + & - & + & & - & - & - & - & - & 63.0 & 28.4 \\
\hline FA20 & M & 11 & + & + & + & + & & + & - & - & + & - & 40.0 & 11.9 \\
\hline FA21 & M & 6 & - & + & - & + & & - & + & + & - & - & 42.0 & 7.2 \\
\hline FA22 & M & 12 & - & + & + & + & $t$ & - & - & + & - & - & 42.0 & 32.6 \\
\hline *FA23 & M & 2 & + & + & - & & & - & - & - & - & - & 61.0 & 40.2 \\
\hline$\because$ FA24 & F & 1 & + & & - & & & - & - & - & - & & 49.6 & 38.6 \\
\hline *FA25 & M & 9 & - & + & + & + & - & - & - & - & - & - & 34.0 & 11.3 \\
\hline FA27 & F & 8 & + & + & - & & & + & - & + & - & - & 44.0 & 7.5 \\
\hline FA28 & M & 5 & - & + & - & + & - & + & - & + & - & - & 52.0 & 21.3 \\
\hline FA29 & M & 10 & - & + & + & + & + & + & - & - & - & - & 31.0 & 23.7 \\
\hline FA30 & M & 6 & - & + & - & + & & - & - & - & - & - & 60.0 & 33.6 \\
\hline FA31 & $F$ & 4 & - & $t$ & - & & & - & & & - & - & 45.0 & 23.3 \\
\hline FA32 & $E$ & 4 & - & + & + & & & & & - & - & + & 52.0 & 50.0 \\
\hline FA33 & M & 4 & + & t+ & + & & & - & - & - & - & - & 32.0 & 8.0 \\
\hline FA37 & $\mathrm{F}$ & 5 & $=$ & + & - & & & - & & - & - & - & 57.0 & 28.9 \\
\hline [B] FA3 & F & 3 & - & - & - & & & - & - & - & - & + & 6.0 & - \\
\hline FA4 & $\mathrm{F}$ & 4 & - & - & - & & & & - & - & - & + & 3.0 & $\cdots$ \\
\hline FA8 & $\mathrm{F}$ & 4 & - & - & - & & - & - & - & - & + & + & 6.5 & 1.5 \\
\hline FA1I & $M$ & 2 & - & - & - & - & & & - & - & - & & 4.0 & 1.1 \\
\hline FA15 & F & 5 & - & \pm & - & & & & - & - & - & - & 9.0 & 1 \\
\hline FA16 & $\mathrm{F}$ & 6 & - & + & - & & - & & - & - & - & - & 10.5 & 1 \\
\hline FA19 & $\mathrm{E}$ & 7 & - & - & - & & - & & - & - & + & + & 7.0 & 1 \\
\hline FA35 & $\mathrm{F}$ & 19 & + & + & - & & & + & & - & - & + & 13.0 & 1 \\
\hline EA36 & $\mathrm{F}$ & 14 & - & \pm & - & & & & - & & - & + & 4.0 & 1 \\
\hline FA38 & M & 11 & - & - & - & - & & - & & - & - & - & 3.0 & 1 \\
\hline FA39 & $M$ & 4 & $\sim$ & \pm & - & + & & \pm & - & - & + & + & 12.0 & 1.9 \\
\hline
\end{tabular}

* Cultured skin fibroblasts. ** Spontaneous frequencies. *** For potentiation factor, see explanation in Table 1. 
the birth incidence of FA homozygotes of 1 in $3.48 \times 10^{5}$ in New York State.

Other recessive genes and implication to the genetic predisposition to cancer

Apart from XP and FA, the AT and BS are among the most cancer-prone conditions of the autosomal recessive trait (German, 1983). As seen in Table 1, like XP and FA, the AT is characterized by the specific sensitivity to X-ray. AT was thus first considered an X-ray analogue of XP and DNA repair deficiency was suggested (Taylor et al., 1976), but no clearly defined DNA repair deficiency has been identified. Interestingly, AT cells exhibit X-ray resistant DNA synthesis (Painter and Young, 1980). When normal cells are irradiated with X-ray, the initiation of DNA replication is delayed but this replication response is lacking in AT cells. The lack of the delay might provide less time for the DNA damage to be repaired before entering $S$ phase and results in increased number of chromatid breaks and hence cell lethality. However, I assume that such X-ray resistant DNA synthesis may not be the sole mechanism for X-ray hypersensitivity of AT. Peripheral blood lymphocytes irradiated in $G_{0}$, but not $G_{1}$, stage, whether they are from normal or AT persons, do not exhibit any significant delay of the onset of DNA replication after PHA stimulation, but AT cells are still highly sensitive to the induction of chromosomal aberrations by X-rays than normal cells (unpublished data). DNA repair deficiency thus still remains to be sought. BS cells are characterized by the high frequency of spontaneous sister chromatid exchanges (Chaganti et al., 1974). Abnormalities in the DNA metabolic pathways have been suggested but no clear evidence for the DNA repair deficiency has been reported.

For the specific autosomal recessive syndromes associated with malignant neoplasms, the identified syndromes may not be numerically important in genetic predisposition to cancer in human populations. Then, there emerges an obvious question as to whether the heterozygotes might have a somewhat increased risk for cancer. Swift (1971) brought about some preliminary evidence indicating that FA heterozygotes might have some increased risk for cancer. However, this has not been substantiated by further studies (Swift et al., 1980). The best evidence available at present may be AT heterozygotes (Swift et al., 1987) and also possibly XP heterozygotes (Swift and Chase, 1979). The experimental approaches to the gene dosage effects on the chromosomal and cellular sensitivity of FA, AT and XP heterozygote are rather controversial. However, it is also likely that the heterozygote expression may not be the same as that of homozygotes. The AT heterozygotes have an increased risk for breast cancer while cancer of lympho-reticular tissues are common in homozygotes (Swift et al., 1987). Berger et al. (1977) described a father with an FA-characteristic malformed thumb whose daughter had full syndrome of FA. It is thus interesting to postulate that the somatic mosaicism, rather than gene dosage, is the underlying mechanism of the occasional heterozygote expression of the recessive gene. Homozygote recombinants in the somatic cells of the heterozygote may be formed by any mechanisms that lead to uniparental disomy such as polyploidization-segregation parasexual cycle, mitotic recombination, non-disjunc-

Vol. 34, No. 1, 1989 
tion and reduplication, and regional gene conversion. Such somatic recombination is not a rare event (Ohno, 1966), and can be enhanced by mutagens (Sasaki, 1978; Eves and Farber, 1983; Yandell et al., 1986).

\section{Chromosome mutation at 13 q14 as a probe for retinoblastoma gene}

Retinoblastoma (RB) is a childhood tumor of the eye. Some tumors occur in hereditary form of the autosomal dominant trait. Substantially all bilateral cases are considered hereditary and inherit mutation from a carrier parent or a healthy parent as a fresh germinal mutation (Vogel, 1979). In the non-hereditary cases, the tumors are usually unilateral and thought to arise as a consequence of somatic mutation in the embryonic retinal cells. The hereditary RB called particular attention in relation to the mutational origin of human cancers since the development of tumor is triggered by a single inherited gene.

In a small fraction of the patients with hereditary $R B$, the $R B$ mutation is microscopically recognizable as a constitutional chromosome structural rearrangement, and provides a unique opportunity to examine the nature and origin of the RB mutations. Table 3 shows the results of our cytogenetic survery for the frequency of constitutional chromosome abnormalities in the unselected RB patients. The constitutional chromosome abnormalities were either interstitial deletion involving $13 \mathrm{q} 14$ or reciprocal translocation with break point at $13 \mathrm{q} 14$. They were de novo origin except for one case in which del(13)(q14) was found both in a patient and in his healthy mother. The types of aberrations are presented in Table 4 together with the selected cases, in which suspected chromosome abnormalities were primary reasons for their referral to the hospital. There was one unique case, in which chromosome 13 was translocated onto late replicating $X$ chromosome with break point at $13 \mathrm{q} 12$ but late replication spreaded over to the translocated chromosome 13 (Ejima et al., 1982a). The cytogenetic findings are all consistent with the idea that the loss of gene function at $13 \mathrm{q} 14$ triggers the development of RB. Recently, the putative RB gene has been cloned (Friend et al., 1986; Lee et al., 1987; Fung et al., 1987). Using cDNA probe of RB gene, it was found that the 10;13 translocation in a patient RB120 directly affected the RB gene (Fung et al., 1987), providing a strong evidence for the crucial role of RB gene in the development of RB tumor.

Table 3. Summary of cytogenetic data from a consequtive survey of 195 RB patients.

\begin{tabular}{lcccc}
\hline \multirow{2}{*}{ Heredity } & Tumor laterality & \multicolumn{2}{c}{ Chromosome constitutions } & \multirow{2}{*}{ Total } \\
\cline { 3 - 4 } & & Normal & Abnormal & \\
\hline \multirow{2}{*}{ Sporadic } & Unilateral & 81 & 1 & 82 \\
& Bilateral & 78 & 8 & 86 \\
Familial & Unilateral & 10 & 0 & 10 \\
& Bilateral & 16 & 1 & 17
\end{tabular}

Data from Ejima et al. (1988). 
Table 4. Types of constitutional chromosome abnormalities and their parental origin in RB patients.

\begin{tabular}{|c|c|c|c|c|}
\hline Patients & Sex & Tumor laterality & Chromosome abnormality & Parental origin \\
\hline RB1 & $\mathrm{F}$ & Bilateral & $\operatorname{del}(13)(q 12 q 22)$ & Paternal \\
\hline RB16 & M & Bilateral & $\operatorname{del}(13)(\mathrm{q} 14 \mathrm{q} 22)$ & n.e. \\
\hline RB162 & $\mathrm{F}$ & Bilateral & $\operatorname{del}(13)(q 14 q 21)$ & Paternal \\
\hline RB221 & $\mathrm{F}$ & Bilateral & $\operatorname{del}(13)(q 14 q 21)$ & Paternal \\
\hline RB182 & M & Unilateral & $\operatorname{del}(13)(q 12 q 14)$ & Paternal \\
\hline RB257 & M & Unilateral & $\operatorname{del}(13)(q 12 q 14)$ & Paternal \\
\hline $\mathrm{RB} 32$ & M & Bilateral & $\operatorname{del}(13)(\mathrm{q} 14)$ & Paternal \\
\hline RB141 & $\mathrm{F}$ & Bilateral & $\operatorname{del}(13)(q 14)$ & Maternal \\
\hline RB88 & M & Bilateral & $\operatorname{del}(13)(q 14) m a t$ & - \\
\hline RB26 & M & Bilateral & Normal/del(13)(q14) & n.e. \\
\hline RB9 & $\mathrm{F}$ & Bilateral & $\mathrm{t}(13 ; \mathrm{X})(\mathrm{q} 12 ; \mathrm{p} 22)$ & Paternal \\
\hline RB165 & M & Bilateral & $\mathrm{t}(6 ; 13)(\mathrm{q} 13 ; \mathrm{q} 14)$ & Paternal \\
\hline $\mathrm{RB} 120$ & $\mathrm{~F}$ & Bilateral & $\mathrm{t}(10 ; 13)(\mathrm{q} 22 ; \mathrm{q} 14)$ & Paternal \\
\hline RB131 & $\mathrm{M}$ & Bilateral & $\mathrm{t}(13 ; 18)(\mathrm{q} 14 ; \mathrm{q} 12)$ & n.e. \\
\hline
\end{tabular}

n.e., not examined.

It is generally recognized that all sporadic bilateral and about $10 \%$ of sporadic unilateral cases are due to fresh mutations that occurred in the germ-line cells of the parents (Vogel, 1979). Excluding mosaic and familial cases, 8 out of $94(8.5 \%)$ of the fresh germinal mutations are, therefore, actually microscopically recognizable chromosome mutations. With this figure, together with the estimated frequency of RB patients due to fresh germinal mutations of $2.19 \times 10^{-5}$ or 1 in $4.6 \times 10^{4}$ live births, we can estimate that about $2.8 \%$ of live births with $\mathrm{RB}$ are expected to have gross chromosome rearrangements of de novo origin (Ejima et al., 1988).

\section{$R B$ gene as a paradigm of tumor supressing genes}

It is well recognized that the patients with hereditary $\mathrm{RB}$ are at remarkably high risk for the development of the second non-ocular tumors after successful treatment for primary RB tumors (Abramson et al., 1979). The second tumors, while more profoundly in the radiation treated area, also appear in the unexposed area, and suggest some intrinsic predisposition and its enhancement by radiation.

Osteosarcoma is the most common second tumors. The involvement of structural anomalies of the RB gene has been shown in some sporadic osteosarcomas and osteosarcoma which appeared in a patient with RB (Hansen et al., 1985; Dryja et al., 1986). Later, in an extensive study using cDNA probe of RB gene, we found that approximately $40 \%$ of the sporadic osteosarcomas had the structural anomalies of RB gene (Toguchida et al., 1988). They were mostly deletion of a segment either spanning over a whole or a part of the RB gene. Types and rates of structural anomalies of RB gene were very comparable to those in RB tumors (Fung et al., 
1987). Particulariy, the presence of interstitial deletion within the RB gene strongly suggests that the mutation of the RB gene is causally related to the development of osteosarcoma. More recently, abnormalities in structure of RB gene have been also noted in the solitary cases of soft tissue sarcomas (Friend et al., 1987), lung carcinomas (Harbour et al., 1988) and breast carcinomas (Lee et al., 1987; T'Ang et al., 1988 ); i.e., the tumors also known as second tumors in the RB patients. These observations indicate that the second non-ocular tumors in hereditary RB patients are the pleiotropic manifestation of the inherited mutation of $\mathrm{RB}$ gene, and more interestingly that mutation of RB gene also plays a role in the development of a variety of common cancers. The gene of this class has been called antioncogene or tumor suppressing genes, and its mutation is assumed to be recessive mutation since its full phenotypic expression is attained by the loss or inactivation of its normal allele (Cavenee et al., 1983). The allele loss is often attained by mitotic recombination, deletion of a region containing normal allele or chromosome loss, and this process can be detected as a loss of heterozygosity of polymorphic loci arround the responsible gene (Cavenee et al, 1983).

Then, why the second tumors are so frequent in the field of radiation treatment? Nove et al. (1981) proposed "repair locus" at 13q14, since they observed that the cultured skin fibroblasts from hereditary or del(13)-type RB patients were sensitive to the cell killing by radiation. However, the increased radiosensitivity of the RB cells have been a matter of considerable debate. We also failed to find any increase in the cellular radiosensitivity as expressed by clonogenic survival after X-ray irradiation (Ejima et al., 1982b).

In the skin fibroblasts from patients with a variety of other hereditary neoplasms and their obligate carriers, there are some indications that the cells are intrinsically rather hypermutable (Sasaki et al., 1980; Sasaki, 1982). Similarly, we found that cultured skin fibroblasts from hereditary RB patients showed an increased frequency of spontaneous chromosome rearrangements (Sasaki et al., 1982, 1988), an increased susceptibility to in vitro transformation by murine sarcoma virus (Miyaki et al., 1983) and a high rate of transfection when transfected with neomycin registant genes (unpublished data). However, unexpectedly, such was not the case for RB patients with chromosome 13 anomalies. The underlying mechanisms of such abnormal cellular manifestation of inherited mutations are not known. According to Dao et al. (1987), the mitotic recombination is a major route to the allele loss during expression of mutation of tumor supressing gene. The genomic instability mentioned above might contribute to the recombinational processes, and recombination itself could be enhanced by radiation, all being in favor of the expression of the RB mutation as malignancy.

\section{Parental sex may affect mutational susceptibility}

The origin of mutation was another concern. The parental origin of chromosome 13 may be determined by examining the morphological characteristics and fluorescence heteromorphism of short arm as well as polymorphic loci as heritable 
markers. Table 4 also shows the parental origin of abnormal chromosome 13 in RB patients thus determined. Surprisingly, in 9 out of 10 informative cases, the abnormal chromosomes were those derived from father. This strong bias toward paternal origin is significantly different from an equal contribution of both sexes $\left(\chi^{2}=4.9\right.$, d.f. $\left.=1, p=0.027\right)$. Since the origin of fresh mutation which can be detected at molecular level remains to be elucidated, it is merely an additional step to imagine, but this finding raises a fundamental question about an equal probability of parental origin of fresh germinal mutations. A strong bias toward paternal origin has been also noted for non-Robertsonian-type chromosome rearrangements in several selected cases of inborn errors (Chamberlin and Magenis, 1980; Butler and Palmer, 1983; Niikawa and Ishikiriyama, 1985).

In non-hereditary tumors, one would expect that the initial somatic mutation would occur equally in maternally and paternally derived chromosomes. However, studying the loss of heterozygosity of polymorphic loci on chromosome 11 in 5 sporadic Wilms tumors, Schroeder et al. (1987) reported loss of maternally derived chromosomes in all cases, indicating the first mutation on paternally derived chromosomes. However, two of their cases are assumed to be hereditary, and thus non-randomness of somatic mutation was not conclusive. We have chosen sporadic osteosarcoma as a model for the somatic mutation, and studied the origin of mutation of RB gene using a series of polymorphic DNA probes on chromosome 13 and CDNA of RB gene (Fig. 1). In a total of 13 informative cases, 12 showed the loss of maternally derived chromosome or chromosome segment involving RB gene (unpublished data). By analogy of the chromosomal reorganization during the development of RB and Wilms tumors, the first mutations were assumed to have occurred on paternally derived chromosomes in 12 cases and on maternally derived chromosome in one case. Again, the ratio is significantly different from the random involvement $\left(\chi^{2}=9.3\right.$, d.f. $\left.=1, p=0.0023\right)$. The strong bias toward paternal chromosomes both for germinal and somatic mutation leads us to a supposition that the post-meiotic stage or very early stages of the development is a major source of the de novo mutation of this sort rather than errors in meiosis.

Evidence has been accumulated to indicate that the parent's sex may affect the behavior of autosomal genes (Surani et al., 1984; Cattanach et al., 1985). The germinal imprinting, probably mediated by some epigenetic process such as de novo methylation and carried over to the post-zygotic stages, can be one of the modifying factors of the susceptibility to post-meiotic germinal and post-zygotic somatic mutations. Such differential susceptibility due to germinal imprinting is highly hypothetical, but consistent with the lack of apparent paternal age effects on the rate of fresh germinal mutation of RB gene (Vogel and Rathenberg, 1975), high vulnerability of sperm chromosomes (Kamiguchi and Mikamo, 1986; Martin et al., 1987), and high frequency of mutational mosaicism in RB patients (Motegi et al., 1982).

Recent progress of molecular dissection of $\mathrm{RB}$ thus revealed a new class of gene which is responsible for the development of tumors. Recent reports also suggests the presence of many such genes which play significant role in the development of 
a
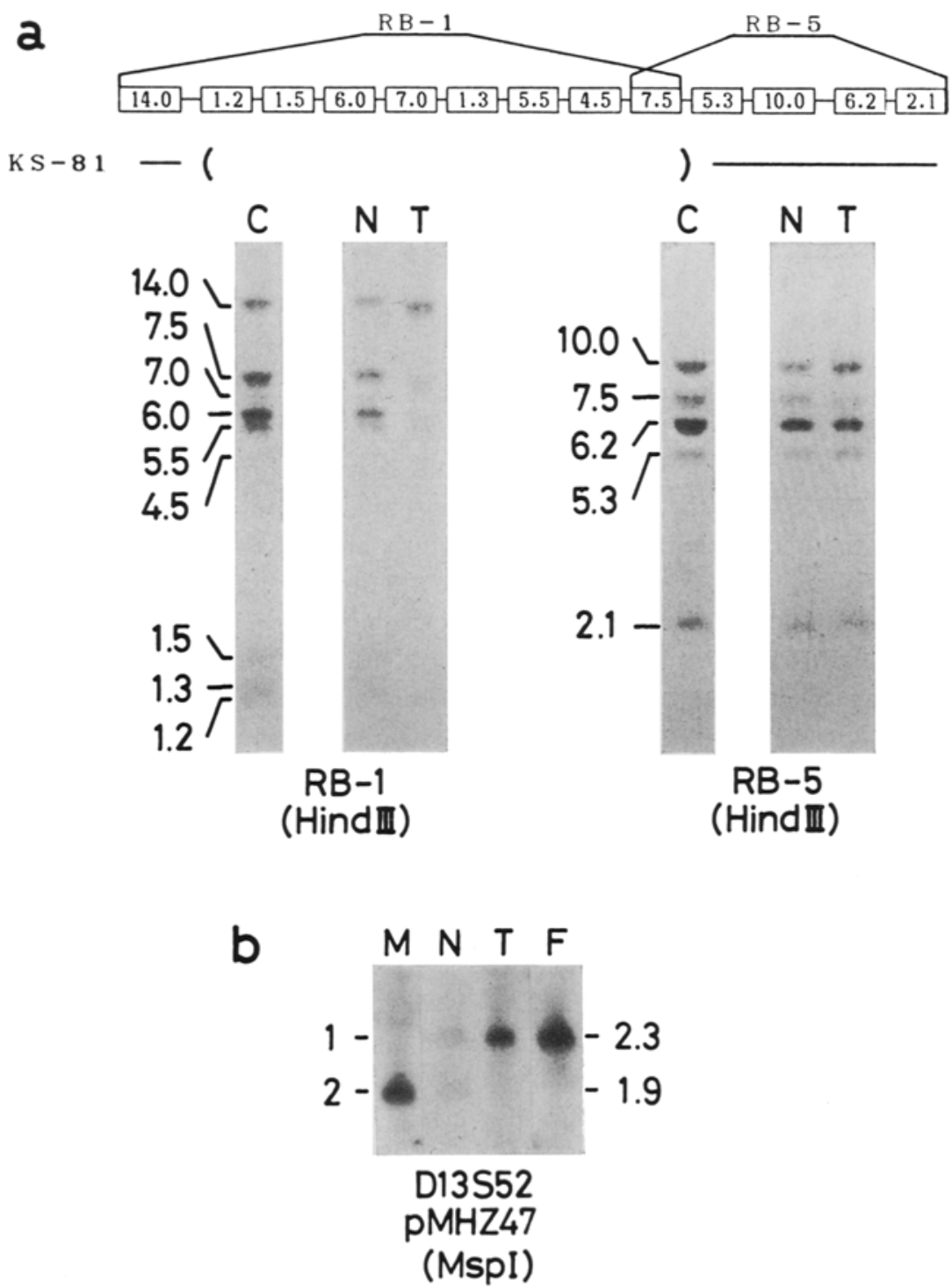

Fig. 1. Southern analysis for the parental origin of mutation of RB'gene in a case of osteosarcoma (KS-81). a: Southern analysis of HindIII digested genomic DNA using cDNA probes of RB gene, RB-1 and RB-5 (Lee et al., 1987) hybridizing with $5^{\prime}$ and $3^{\prime}$ portions of RB gene, respectively. Note the homologous loss of some HindIII fragments in the tumor (T). Abnormality was interstitial deletion. within $\mathrm{RB}$ gene as schematically shown on the top. No structural anomaly of RB gene is detected in the constitutional cells $(N)$ of the patient, providing an evidence for somatic mutation. $\mathrm{C}$ is control. b: Southern analysis of polymorphic loci on chromosome 13 in constitutional cells of mother (M) and father (F), and constitutional $(\mathrm{N})$ and tumor $(\mathrm{T})$ cells of the patient. Note that father is homozygous for allele 1 and mother is homozygous for allele 2 . The patient is constitutionally heterozygous but maternally derived allele (allele 2) is missing in tumor, indicating that deletion mutation of $\mathrm{RB}$ gene occurred on paternally derived chromosome. 
a variety of common cancers. Germinal mutation of such gene will link to the birth of rare genetic disease of hereditary neoplasm, but somatic mutation of the same gene will link to the development of common cancer or play a role in tumor progression as a modulator gene.

Acknowledgments I am indebted to numerous colleagues, collaborators, and students for the invaluable contributions they have made to this research. Most of our works quoted in this paper were supported by Grants-in-Aid from the Ministry of Education, Science and Culture, the Ministry of Health and Welfare of Japan, and the Princess Takamatsu Cancer Research Fund.

\section{REFERENCES}

Abramson, D.H., Ronner, H.J. and Elsworth, R.M. 1979. Second tumors in nonirradiated bilateral retinoblastoma. Am. J. Ophthalmol. 87: 624-627.

Berger, R., Bussel, A. and Schenmetzler, C. 1977. Somatic segregation and Fanconi anaemia. Clin. Genet. 11 : 409-412.

Butler, M.G. and Palmer, C.G. 1983. Parental origin of chromosome 15 deletion in Prader-Willi syndrome. Lancet i: $1285-1286$.

Cattanach, B.M. and Kirk, M. 1985. Differential activity of maternally and paternally derived chromosome regions in mice. Nature 315: 496-498.

Cavenee, W.K., Dryja, T.P., Phillips, R.A., Benedict, W.F., Godbout, R., Gallie, B.L., Murphree, A.L., Strong, L.C. and White, P.L. 1983. Expression of recessive alleles by chromosomal mechanisms in retinoblastoma. Nature 305: 779-784.

Chaganti, R.S.K., Schonberg, S. and German, J. 1974. A manifold increase in sister chromatid exchanges in Bloom's syndrome lymphocytes. Proc. Natl. Acad. Sci. USA 71: 4508-4512.

Chamberlin, J. and Magenis, R.E. 1980. Parental origin of de novo chromosome rearrangements. Hum. Genet. 53: 343-347.

Cleaver, J.E. 1968. Defective repair replication of DNA in xeroderma pigmentosum. Nature 218: $652-656$.

Dallapiccola, B., Alimena, G., Brinchi, V., Isacchi, G. and Gandini, E. 1980. Absence of chromosome heterogeniety between classical Fanconi's anemia and the Estren-Dameshek type. Cancer Genet. Cytogenet. 2: 349-360.

Dao, D.D., Schroeder, W.T., Chao, L.-Y., Kikuchi, H., Strong, L.C., Riccardi, V.M., Pathak, S., Nichols, W.W., Lewis, W.H. and Sanders, G.F. 1987. Genetic mechanisms of tumor-specific loss of 11p DNA sequences in Wilms tumor. Am. J. Hum. Genet. 41: 202-217.

Dryja, T.P., Rapaport, J.M., Epstein, J., Goorin, A.M., Weichselbaum, R., Koufos, A. and Cavenee, W.K. 1986. Chromosome 13 homozygocity in osteosarcoma without retinoblastoma. Am. J. Hum. Genet. 38: 59-66.

Ejima, Y., Sasaki, M.S., Kaneko, A. and Tanooka, H. 1988. Types, rates, origin and expressivity of chromosome mutations involving $13 \mathrm{q} 14$ in retinoblastoma patients. Hum. Genet. 79: $118-123$.

Ejima, Y., Sasaki, M.S., Kaneko, A., Tannoka, H., Hara, Y., Hida, T. and Kinoshita, Y. 1982a. Possible inactivation of part of chromosome 13 due to $13 \mathrm{qX}$ translocation associated with retinoblastoma. Clin. Genet. 21: 357-361.

Ejima, Y., Sasaki, M.S., Utsumi, H., Kaneko, A. and Tanooka, H. 1982b. Radiosensitivity of fibroblasts from patients with retinoblastoma and chromosome-13 anomalies. Mutation Res. 103: $177-184$.

Evans, H.J. and Scott, D. 1969. The induction of chromosome aberrations by nitrogen mustard and its dependence on DNA synthesis. Proc. Roy. Soc. (London), Ser. B. 173: 491-512.

Eves, E.M. and Farber, R.A. 1983. Expression of recessive Aprt- mutations in mouse CAK cells resulting from chromosome loss and duplication. Somatic Cell Genet. 9: 771-778. 
Friend, S.H., Bernards, R., Rogelj, S., Weinberg, R.A., Rapaport, J.M., Alber, D.M. and Dryja, T.P. 1986. A human DNA segment with properties of the gene that predisposed to retinoblastoma and osteosarcoma. Nature 323: $643-646$.

Friend, S.H., Horowitz, J.M., Gerber, M.R., Wang, X.-F., Bogenmann, E., Li, F.P. and Weinberg, R.A. 1987. Deletion of a DNA sequence in retinoblastomas and mesenchymal tumors: organization of the sequence and its encoded protein. Proc. Natl. Acad. Sci. USA 84: 9059 9063.

Fujiwara, Y., Tatsumi, M. and Sasaki, M.S. 1977. Cross-link repair in human cells and its possible defect in Fanconi's anemia cells. J. Mol. Biol. 113: 635-649.

Fung, Y.-K.T., Murphree, A.L., T'Aang, A., Qian, J., Hinrichs, S.H. and Benedict, W.F. 1987. Structural evidence for the authenticity of the human retinoblastoma gene. Science 236: 1657-1661.

German, J. 1969. Chromosomal breakage syndromes. Birth Defect 5: 117-130.

German, J.L. 1983. Patterns of neoplasia associated with the chromosome breakage syndromes. In Chromosome Mutation and Neoplasia, German, J.L., ed., pp. 97-134, Alan R. Liss, New York..

Gruenert, D.C. and Cleaver, J.E. 1985. Repair of psoralen-induced cross-links and monoadducts in normal and repair-deficient human fibroblasts. Cancer Res. 45: 5399-5404.

Hansen, M.F., Koufos, A., Gallie, B.L., Phillips, R.A., Fodstad, O., Brogger, A., Geddle-Dahl, T. and Cavenee, W.K. 1985. Osteosarcoma and retinoblastoma: a shared chromosomal mechanism revealing recessive predisposition. Proc. Natl. Acad. Sci. USA 82: 6216-6220.

Harbour, J.W., Lai, S.-L., Whang-Peng, J., Gazdar, A.F., Minna, J.D. and Kaye, F.J. 1988. Abnormalities in structure and expression of the human retinoblastoma gene in SCLC. Science 241: $353-357$.

Imaizumi, Y., Shinozaki, N. and Aoki, H. 1975. Inbreeding in Japan: results of a nation-wide survey, Jpn. J. Human Genet. 20: 91-107.

Joenje, H., Arwert, F., Eriksson, A.W., De Koning, H. and Oostra, A.B. 1981. Oxygen dependence of chromosomal aberrations in Fanconi's anaemia. Nature 290: 142-143.

Kamiguchi, Y. and Mikamo, K. 1986. An improved, efficient method for analyzing human sperm chromosomes using zona-free hamster ova. Am. J. Hum. Genet. 38: 724-740.

Lee, W.-H., Bookstein, R., Hong, F., Young, L.J., Shew, J.-Y. and Lee, E.Y.-H.P. 1987. Human retinoblastoma susceptibility gene: cloning, identification, and sequence. Science 235: 13941399.

Makino, S., Sasaki, M.S. and Tonomura, A. 1964. Cytological studies of tumors. XL. Chromosome studies in fifty-two human tumors. J. Natl. Cancer Inst. 32: 741-777.

Matsumoto, A., Vos, J.-M.H. and Hanawalt, P.C. 1989. Repair analysis of mitomycin C induced DNA crosslinking in ribosomal RNA genes in lymphoblastoid cells from Fanconi's anemia patients. Mutation Res., in press.

Martin, R.H., Radenaker, A.W., Hildebrand, K., Long-Simpson, L., Peterson, D. and Yamamoto, J. 1987. Variation in the frequency and type of sperm chromosomal abnormalities among normal men. Hum. Genet. 77: 108-114.

Miyaki, M., Akamatsu, N., Ono, T. and Sasaki, M.S. 1983. Susceptibility of skin fibroblasts from patients with retinoblastoma to transformation by murine sarcoma virus. Cancer Lett. 18: $137-142$.

Motegi, T. 1982. High rate of detection of $13 \mathrm{q} 14$ deletion mosaicism among retinoblastoma patients (using more extensive methods). Hum. Genet. 61: 95-97.

Niikawa, N. and Ishikiriyama, S. 1985. Clinical and cytogenetic studies of the Prader-Willi syndrome. Evidence of phenotype-karyotype correlation. Hum. Genet. 69: 22-27.

Nove, J., Nichols, W.W., Weichselbaum, R.R. and Little, J.B. 1981. Abnormalities of human chromosome 13 and in vitro radiosensitivity. Mutation Res. 84: 157-167.

Obe, G., Natarajan, A.T., Meyers, M. and Hertog, D. 1979. Induction of chromosomal aberrations in peripheral lymphocytes of human blood in vitro, and of SCEs in bone-marrow cells of mice in vivo by ethanol and its metabolite acetaldehyde. Mutation Res. 68: 291-294. 
Ohno, S. 1966. Cytologic and genetic evidence of somatic segregation in mammals, birds, and fishes. In Vitro 2: 46-60.

Painter, R.B. and Young, B.R. 1980. Radiosensitivity in ataxia-telangiectasia: a new explanation. Proc. Natl. Acad. Sci. USA 77: 7315-7317.

Papadopoulo, D., Averbeck, D. and Moustacchi, E. 1987. The fate of 8-methoxypsoralen-photoinduced DNA interstrand crosslinks in Fanconi's anemia cells of defined genetic complementation group. Mutation Res. 184: 271-280.

Poll, E.H.A., Arwert, F., Joenje, H. and Wanamarta, A.H. 1985. Differential sensitivity of Fanconi anaemia lymphocytes to the clastogenic action of cis-diamminedichloroplatinum (II) and transdiamminedichloroplatinum (II). Hum. Genet. 71: 206-210.

Sasaki, M.S. 1973. DNA repair capacity and susceptibility to chromosome breakage in xeroderma pigmentosum cells. Mutation Res. 20: 291-293.

Sasaki, M.S. 1975. Is Fanconi's anaemia defective in a process essential for the repair of DNA cross-link? Nature 257: 501-503.

Sasaki, M.S. 1978. Fanconi's anemia: a condition possibly associated with a defective DNA repair. In DNA Repair Mechanisms, Hanawalt, P.C., Friedberg, E.C. and Fox, C.F., eds., pp. 675684, Academic Press, New York.

Sasaki, M.S. 1978. Chemical-induced chromosome recombination by polyploidization-segregation parasexual cycle. Mutation Res. 54: 224-225.

Sasaki, M.S. 1982. Dominantly expressed procancer mutations and induction of chromosome rearrangements. Prog. Mutation Res. 4: 75-84.

Sasaki, M.S., Ejima, Y., Kaneko, A. and Tanooka, H. 1988. Genetic and cytogenetic aspects of retinoblastoma mutation and its relevance to the development of tumor. Gann Monogr. Cancer Res. 35: 13-28.

Sasaki, M.S. and Norman, A. 1966. DNA fibers from human lymphocyte nuclei. Exp. Cell Res. 44: 642-645.

Sasaki, M.S., Toda, K. and Ozawa, A. 1977. Role of DNA repair in the susceptibility to chromosome breakage and cell killing in cuitured human fibroblasts. In Biochemistry of Cutaneous Epidermal Differentiation, Seiji, M. and Bernstein, I.A., eds., pp. 167-180, Univ. Tokyo Press, Tokyo.

Sasaki, M.S. and Tonomura, A. 1969. Chromosomal radiosensitivity in Down's syndrome. Jpn. J. Human Genet. 14: 81-92.

Sasaki, M.S. and Tonomura, A. 1973, A high susceptibility of Fanconi's anemia to chromosome breakage by DNA cross-linking agents. Cancer Res. 33: 1829-1836.

Sasaki, M.S., Tsunematsu, Y., Utsunomiya, J. and Utsumi, J. 1980. Site-directed chromosome rearrangements in skin fibroblasts from persons carrying genes for hereditary neoplasms. Cancer Res. 40: 4796-4803.

Schroeder, T.M., Anschutz, F. and Knopp, A. 1964. Spontane Chromosomenaberrationen bei familiarer Panmyelopathie. Hunangenetik 1: 194-196.

Schroeder, W.T., Chao, L.-Y., Dao, D.D., Strong, L.C., Pathak, S., Riccardi, V., Lewis, W.H. and Saunders, G.F. 1987. Nonrandom loss of maternal chromosome 11 alleles in Wilms tumors. Am. J. Hum. Genet. 40: 413-420.

Schuler, D., Kiss, A. and Fabian, F. 1969. Chromosomal peculiarities and "in vitro" examinations in Fanconi's anaemia. Humangenetik 7: 314-322.

Surani, M.A.H., Barton, S.C. and Norris, M.L. 1984. Development of reconstituted mouse eggs suggests imprinting of the genome during gametogenesis. Nature 308: 548-550.

Swift, M. 1971. Fanconi's anaenia in the genetics of neoplasia. Nature 230: 370-373.

Swift, M., Caldwell, R.J. and Chase, C. 1980. Reassessment of the cancer-predisposition of Fanconi's anemia heterozygotes. J. Natl. Cancer Inst. 65: 863-867.

Swift, M. and Chase, C. 1979. Cancer in families with xeroderma pigmentosum. J. Natl. Cancer Inst. 62: 1415-1421. 
Swift, M., Reitnauer, P.J., Morrell, D. and Chase, C. 1987. Breast and other cancers in families with ataxia-telangiectasia. New Engl. J. Med. 316: 1289-1294.

T'Ang, A., Varley, J.M., Chakraborty, S., Murphree, A.L. and Fung, Y.-K.T. 1988. Structural rearrangement of the retinoblastoma gene in human breast carcinoma. Science 242: 263-266.

Taylor, A.M.R., Metcalfe, J.A., Oxford, J.M. and Harnden, D.G. 1976. Is chromatid-type damage in ataxia telangiectasia after irradiation at $\mathrm{G}_{0}$ a consequence of defective repair? Nature 260: $441-443$.

Toguchida, J., Ishizaki, K., Sasaki, M.S., Ikenaga, M., Sugimoto, M., Kotoura, Y. and Yamamuro, T. 1988. Chromosomal reorganization for the expression of recessive mutation of retinoblastoma susceptibility gene in the development of osteosarcoma. Cancer Res. 48: 39393943.

Yandell, D.W., Dryja, T.P. and Little, J.B. 1986. Somatic mutations at a heterozygous autosoma 1 locus in human cells occur more frequently by allele loss than by intragenic structural alterations. Somatic Cell Mol. Genet. 12: 255-263.

Yonei, S. and Furui, H. 1981. Lethal and mutagenic effects of malondialdehyde, a decomposition product of peroxidized lipids, on Escherichia coli with different DNA-repair capacities. Mutation Res. 88: 23-32.

Vogel, F. 1979. Genetics of retinoblastoma. Hum. Genet. 52: 1-54.

Vogel, F. and Rathenberg, R. 1975. Spontaneous mutation in man. Adv. Hum. Genet. 5: 223-318. 